\title{
Parallel Optimization of the Balancing and Sequencing for Mixed-model Assembly Lines
}

\author{
Wei Zhang ${ }^{1}$, Liang Hou ${ }^{1}$,Yawen $\mathrm{Gan}^{1}$, Changhua $\mathrm{Xu}^{2}$,Xiangjian $\mathrm{Bu}^{1}$,Haojing Lin $^{1}$ \\ ${ }^{1}$ School of Aerospace Engineering, Xiamen University, Fujian 361000, China. E-mail: zhangw@stu.xmu.edu.cn \\ ${ }^{2}$ Xiamen KingLong United Auto Industry Co., Ltd. , Fujian 361023, China. E-mail: xuch@mail.king-long.com.cn
}

\begin{abstract}
The traditional Mixed-model Assembly Lines (MMALS) balancing and sequencing serial design methods are difficult to adapt to rapidly changing requirements. From the perspective of the parallel design of balancing and sequencing, a mixed integer linear programming model for MMALS balancing and sequencing is proposed. An improved particle swarm optimization (PSO) algo-rithm was proposed, in the process of updating the optimal solution, the simulated annealing (SA) algorithm is added to make it possible to jump out of the local optimum with a certain probability and expand the solution selection to the entire population. Based on the algorithm, random coding and ascending decoding methods are proposed, the number of products and the number of tasks are coded and decoded at the same time. Verify the effectiveness of the algorithm by an example.
\end{abstract}

Keywords: Mixed-model assembly lines, Balancing, Sequencing, Particle swarm optimization algorithm

\section{Introduction}

With fierce competition in the current market, manufacturers need to optimize their manufacturing processes to adapt to this change. Mixed-model Assembly Lines (MMALS) are favored by various manufacturers because they can provide a variety of products and meet the customized needs of customers in an intelligent manner [1,2]. MMALS is a line that suitable for products with similar structures or manufacturing processes. The MMALS involves two dominant problems, balancing and sequencing [3]. Mixed-model assembly line balancing (MMALB) is the allocation of a limited number of tasks to several workstations, and each task is assigned only once, the transmission system connects these workstations together and moves products between them [4]. Mixed-model sequencing problem (MMSP) put the high and low load products into the production line alternately, to achieve the maximum workload required to complete the production plan within a specified period of time and to minimize the overload of workstations $[5,6]$.

The Assembly line balancing problem (ALBP) can be traced back to Salvison's work (1955) and Jackson (1956) $[7,8]$. Generally, the main objective of MMALB is to minimise the sum of the differences between the cycle time and individual workloads and minimise the total idle time of the line by minimising the number of required stations and/or the cycle time [9]. MMSP was first proposed by Wester and Kilbridge in 1963, indicating that a series of products were put to the assembly line in a certain order under constraint conditions and achieved the desired goal, MMSP has been proved to be a typical NP problem [10].

In the traditional production planning process, balancing and sequencing are interacted. The optimization results for balancing can be used for sequencing, and rebalancing has to be done once the problems arise from sequencing. The two problems are iteratively evolved until a satisfactory result is obtained [11,12]. However, many studies have dealt with these two issues separately.

For the MMALB problem, combined precedence diagram is a common solution for MMALS optimization. It obtains the task weighted operation time according to the product demand ratios, and therefore, converts the MMALS into a single product assembly line [13]. However, the demand for products is often not based on a predetermined proportion. Therefore, the assembly line rebalancing was proposed $[14,15]$, which considers production efficiency and adjustment cost of rebalancing, assembly balance efficiency, equipment mobile cost, cost of artificial training due to task re-assignment [16-18].

For MMSP, a multi-objective function is usually established and solved by optimization algorithm. For example, the adaptive genetic algorithm is used to solve the optimization model with objectives of the total work efficiency and installation costs [19]. Ponnambalam et.al [20] used the Pareto micro-mirror genetic algorithm to optimize multi-objectives of the total efficiency, constant usage rate of parts and total installation cost. Ref.[21] present a formulation for the MMSP-W (Mixed model sequencing problem with workload minimisation) for production lines with serial workstations, and solve the proposed problem through BDP (Bounded Dynamic Programming). An ACOEA algorithm with the taboo search and elitist strategy is proposed to form an optimal sequence of multi-product models which can minimise deviation between the ideal material usage rate and the practical material usage rate [22]. LU et.al [23] developed a mathematical model to minimize the time of product change, overloading time and the idle time of the station, and solved this model by a hybrid artificial ant colony algorithm.

There are also some studies that analyze the balancing and sequencing at the same time. For example, using a layered approach [24,25]. First, balancing is firstly solved as an upper-level problem, and the sequencing solution is limited by the balance result. Ref. [26] proposes an innovative hierarchical method for balancing and sequencing, using a flexible employee called "fast operator", and a heuristic method based on Vogel approximation to solve MMSP. The above method actually breaks a complex problem into two separate sub-problems. Although it considers two issues at the same time, this method will certainly reduce the search space in the solution process, making it difficult to find the best solution. 
In summary, balancing and sequencing are two main issues in the MMALS. The balancing problem optimizes the proportion of products, and the sequencing problem that is based on the balancing results deals with a multiobjective optimization model. However, with the advent of the personalization era, the customer's demand for varieties and quantities is unpredictable and random, and the delivery period is becoming tighter. Traditional serial iterative update programs that perform sequencing after balancing cannot satisfy the above requirements.

Therefore, in order to meet the actual production needs and various customers' requirements, a parallel production line planning method is used to optimize the balancing and sequencing problems at the same time. The improved PSO algorithm is applied for parallel optimization of balancing and sequencing. The algorithm is verified and compared with published work in literature. The results show that the proposed production line planning method offers a universal method to model the true demands for the MMALS.

The remainder of this paper is organised as follows. In Section 2, we have established a model that combines the balancing and sequencing of MMALS. In section 3, we propose a improved PSO algorithm and problem solving method. Section 4 verifies the rationality of the model theory and the effectiveness of the algorithm through case studies. Finally, we present conclusions with limitations, and describe future work in Section 5.

\section{Development of the mixed-model assembly line model}

There are $\boldsymbol{M}$ kinds of products produced on MMALS. Within a period of time, the total demand for $\boldsymbol{M}$ kinds of products is $\boldsymbol{D}$ units. The demand for each kind is $\boldsymbol{m} \in$ $\{\mathbf{1}, \mathbf{2}, \cdots, \boldsymbol{m}, \cdots, \boldsymbol{M}\}$ units, $\boldsymbol{D}=\sum_{\boldsymbol{m}=\mathbf{1}}^{\boldsymbol{M}} \boldsymbol{D}_{\boldsymbol{m}}$. Assume that $\boldsymbol{g}$ is the greatest common factor of product demand $\boldsymbol{D}_{\boldsymbol{m}}$. Hypothesis $\boldsymbol{d}_{m}=\boldsymbol{D}_{\boldsymbol{m}} / \boldsymbol{g}, \boldsymbol{d}=\sum_{m=1}^{M} \boldsymbol{d}_{m}$, and $\left(\boldsymbol{d}_{1}, \boldsymbol{d}_{2}, \cdots\right.$ $\left., \boldsymbol{d}_{\boldsymbol{m}} \cdots, \boldsymbol{d}_{\boldsymbol{M}}\right)$ is the minimum ratio of product demand, sequencing the $\boldsymbol{d}$ products and generate a sequence loop. Putting this sequence of cycle into production $\boldsymbol{g}$ times, this will achieve the purpose of sequencing $\boldsymbol{D}$ products.

The purpose of balancing and sequencing of MMALS is to make the line in a continuous and stable working condition in the assembly process, this condition can be divided into long-term relative static balance and shortterm dynamic balance. Therefore, consider the combination of multiple indexes to evaluate the efficiency and program of MMALS, makes the load balancing among workstations (balance between stations), the load balancing of different products within each station (station's internal balance), instantaneous load balancing (dynamic balance) between stations in different conditions. The specific optimization goals are as follows:

Load balancing among workstations is very important in MMALS. Usually, when the load is more balanced, the waiting time and blocking time of each workstation are shorter. Therefore, this paper designs the optimization target of load balancing for each workstation. The objective function based on load balancing of workstations can be described as:

$$
J_{1}=\sqrt{\frac{\sum_{k=1}^{S}\left[\sum_{m=1}^{M} q_{m} T_{m k}-\frac{\sum_{j=1}^{S} \sum_{m=1}^{M} q_{m} T_{m j}}{S}\right]^{2}}{S}}
$$

$J_{1}$ represents the mean of the variance between the comprehensive average working time of each stations and the overall average working time of all stations. $\boldsymbol{T}_{\boldsymbol{m} \boldsymbol{j}}$ indicates the total working time of the $\boldsymbol{m}$ product at the $\boldsymbol{j}$ station. $\boldsymbol{q}_{\boldsymbol{m}}$ indicates the percentage requirement of the $\boldsymbol{m}$ th product. $\boldsymbol{T}_{\boldsymbol{m} \boldsymbol{k}}$ indicates the total working time of the $\boldsymbol{m}$ th product at the $\boldsymbol{k}$ station.

The operation time of the same operation elements of different varieties on the mixed line is different, so that the assembly time of workstations is different when assembling different varieties. Therefore, when assigning all the operation elements to each workstation of the assembly line, the fluctuation of assembly time in different workstations should be considered, so that the fluctuation of the assembly time is minimized.The objective function aiming at station's internal balance can be described as:

$$
J_{2}=\frac{\sum_{j=1}^{S}\left[\frac{\sum_{m=1}^{M}\left(q_{m} \sum_{i=1}^{N} Q_{i m} x_{i j} t_{i m}-\overline{T_{j}}\right)^{2}}{M}\right]^{\frac{1}{2}}}{S}
$$

$J_{2}$ stands for the deviation between the weighted working time for different products at $\boldsymbol{j}$ station and the total weighted average working time of the station. $\overline{\boldsymbol{T}}_{\boldsymbol{j}}=$ $\sum_{i=1}^{N} \sum_{m=1}^{M} \boldsymbol{Q}_{i m} \boldsymbol{q}_{m} \boldsymbol{z}_{i j} \boldsymbol{t}_{i m}$, indicates the weighted average working time of all tasks assigned to the $\boldsymbol{j}$ station. $\boldsymbol{z}_{\boldsymbol{j} \boldsymbol{i}}$ is used to determine whether the $\boldsymbol{j}$ station is assigned $\boldsymbol{i}$ task, value 1 or $0 . \boldsymbol{t}_{\boldsymbol{i m}}$ indicates the working time of the $\boldsymbol{i}$ task of the $\boldsymbol{m}$ product. $\boldsymbol{Q}_{\boldsymbol{i} \boldsymbol{m}}$ indicates whether the $\boldsymbol{m}$ product has $\boldsymbol{i}$ task, value 1 or $0 . \boldsymbol{x}_{\boldsymbol{i} \boldsymbol{j}}$ is used to determine whether task $\boldsymbol{i}$ is assigned to workstation $\boldsymbol{j}$.value 1 or 0 .

After confirming the sequencing of production, a variety of states will be formed based on the different product combinations that may occur at each workstation. The number of states is the same as the sum of the minimum proportional numbers of each product. For example, if there are $\boldsymbol{d}$ products forming a loop, then there are $\boldsymbol{d}$ states. Because the operating time of the products corresponding to each workstation is different under a certain state, this will affect the time for blocking and waiting. Assuming that the working time of a workstation on a MMALS is the largest in the $\boldsymbol{z}$ state, the other workstations will have to wait for the workstation to complete the work before they can be moved as a whole.

Therefore, in each state, the balance between the working time of each workstation and the maximum working time of a workstation under this state is a goal function that needs to be considered. The objective function is set up as follows:

$$
J_{3}=\sqrt{\sum_{z=1}^{d} \frac{\sum_{k=1}^{S}\left[t_{z k}-M A X t_{z k}\right]^{2}}{s d}}
$$

$\boldsymbol{t}_{\boldsymbol{z} \boldsymbol{k}}$ represents the task time assigned by the $\boldsymbol{k}$ station in the $\boldsymbol{z}$ condition. $\boldsymbol{M} \boldsymbol{A} \boldsymbol{X} \boldsymbol{t}_{\boldsymbol{z} \boldsymbol{k}}$ represents the maximum assignment time of all workstations in the $\boldsymbol{z}$ condition. $\boldsymbol{d}$ indicates that when a product is configured in proportion, 
there are different serial product corresponding status numbers on the workstation generated by the sequencing.

The overall purpose of balancing and sequencing is to make the working time of all workstations as balanced as possible, and to reduce idle time at each workstation. Therefore, the overall objective function of equation (4) is established. The objective functions 1, 2 and 3 are balance between stations, station's internal balance and dynamic balance.

$$
M I N J=\omega_{1} J_{1}+\omega_{2} J_{2}+\omega_{3} J_{3}
$$

Among them, the impact of the objective function 1 and 2 on the output time of the product is indirect, and the dynamic balance directly affects the output time of the product. $\boldsymbol{\omega}_{1}+\boldsymbol{\omega}_{2}+\boldsymbol{\omega}_{3}=1, \boldsymbol{\omega}_{1} 、 \boldsymbol{\omega}_{2} 、 \boldsymbol{\omega}_{3}$ are userdefined weighting factors which allow decision-makers to decide the significance levels of objectives.

$$
\sum_{j=1}^{S} X_{i j} \leq 1, i=1,2,3 \cdots, N
$$

$$
\begin{array}{r}
\sum_{j=1}^{S} j x_{i j} \leq \sum_{j=1}^{S} \\
x_{i m} \in\{0,1\} \forall i, j ; \\
\boldsymbol{Q}_{i m} \in\{0,1\} \forall i, m ;
\end{array}
$$

$\boldsymbol{P R} \boldsymbol{E}(\boldsymbol{l})$ represents a task set that prioritizes task $\boldsymbol{l}$ based on task priority. Equation (5) ensures that each task can only be assigned to one workstation. Equation (6) ensures that the task allocation meets the task priority. Equation (7) indicates that the decision variable assigned to each task on the workstation is $0 / 1$. Equation (8) indicates that the decision variable for whether the $\boldsymbol{m}$ product contains the $\boldsymbol{i}$ task is $0 / 1$.

\section{Algorithm design}

PSO is a random optimization technology based on population, which is proposed by Kennedy and Eberhart (1995), discuss the application of PSO in artificial neural network weight training and proves the good performance of the algorithm [27]. The core of PSO is to improve social information sharing among particles in a group. Each particle moves in a multi-dimensional search space, and the speed for each particle is constantly updated according to the experience of this particle and the experience of the best particle. The particle with the best solution will be saved in each iteration. This solution is called as the local optimum (pbest). The optimal solution in all particles is treated as the global optimum (gbest).

MMALS balancing and sequencing problems are NPhard problems. Therefore, an adaptable, fast-solving algorithm is needed to solve these problems. PSO has the characteristics of simple algorithm rules, fast convergence speed and few adjustable parameters, and is preferable to solve multi-objective optimization problems. Although PSO has the above advantages, its convergence speed at the later period is easy to decrease. To avoid this issue, adjustment of the inertia weight coefficient can be used, but it is faced with premature convergence. Based on this, a new mechanism called joint selection is used to determine the algorithm selection method (Fig.1).Based on the standard PSO algorithm, this method judges whether to enter the SA algorithm to continue the search by introducing the judgment value of the average variation of the overall fitness, thus avoiding premature convergence. The basic idea of the simulation algorithm is to start from a given solution and generate another solution from the neighborhood of the solution randomly. The Metropolis acceptance criteria allow the objective function to accept the worsening solution with certain probability, so that the algorithm has the opportunity to break away from the local optimum.

For unimodal functions, PSO can advance rapidly to the optimal value at the initial stage, but it converges slowly near the optimal value. For multimodal functions, local convergence is more likely to occur. In order to avoid this stagnation, the average change in overall fitness $\Delta \boldsymbol{f}=\sqrt{\sum_{i=1}^{P}\left(J_{i}-\bar{J}\right)^{2} / P}$ is increased. $J_{i}$ represents the target function value of each particle under the current generation. $\bar{J}$ represents the average value of the objective function of each particle under the current generation. $\boldsymbol{P}$ represents the size of the population. If $\Delta \boldsymbol{f}<\boldsymbol{c}$ ( $\boldsymbol{c}$ is used as a criterion for judging whether the algorithm enters convergence), accept new values, Otherwise, using Metropolis criteria, if $\exp (-\Delta f / T)>\operatorname{rand}(0,1)$, then accept the new value of the worsening solution. If $\exp (-\Delta \boldsymbol{f} / \boldsymbol{T}) \leq \boldsymbol{r a n d}(0,1)$, refused worsening solution, and updated $\boldsymbol{p}_{\boldsymbol{l d}}, \boldsymbol{p}_{\boldsymbol{g d}}$.

The cooling temperature is the key parameter to jump out of the local extremum, which directly affects the acceptance criteria. In this paper, the constant coefficient method is adopted in the cooling strategy.

$$
T_{f+1}=\rho T_{f}
$$

$\boldsymbol{\rho}$ is generally between 0.8 and 0.99 . This method is simple and effective for finding approximate optimal solutions. Finally, judging whether the termination condition $\boldsymbol{t}<\boldsymbol{T}_{\text {end }}$ is satisfied, if so, enter the current solution as the optimal solution and end the program. If not, update the temperature $\boldsymbol{t}$ and return to calculate the fitness.

The SA algorithm is introduced into the iterative process and the deteriorated solution is accepted according to the probability. This conforms to the idea of parallel simulated annealing and improves the speed of annealing algorithm. 


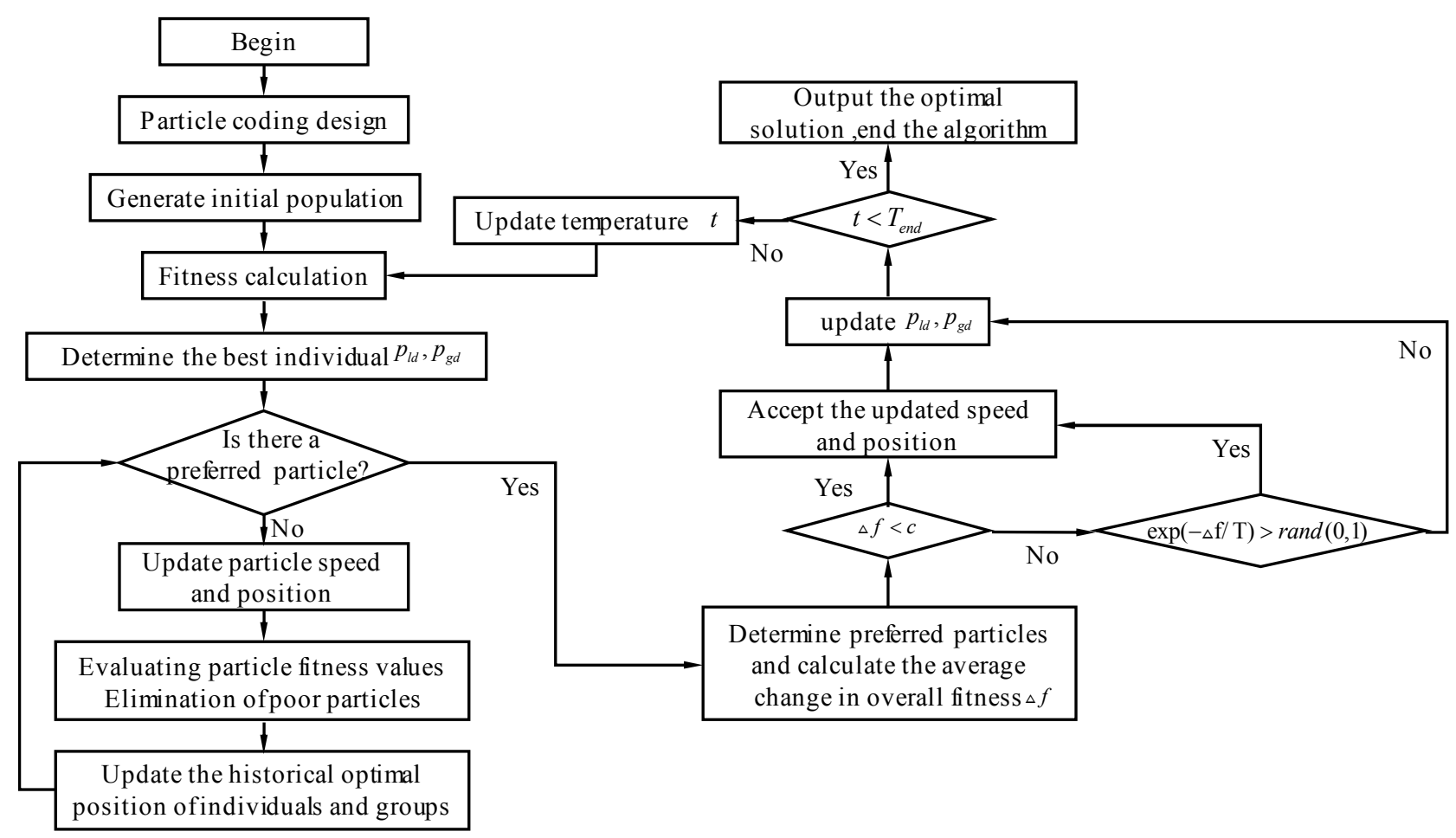

Fig. 1 Flow chart of particle swarm algorithm combined with simulated annealing

\section{Case Studies}

The experimental data from Ref. [15] is used to verify the proposed method and algorithm. The ratio of three products $\mathrm{A}, \mathrm{B}$ and $\mathrm{C}$ on one production line is $4: 2: 3$. The mixed line contains 39 tasks and the number of workstations is 7 . The time used for each task of a product is shown in Tab.1, and the combined precedence diagram is shown in Fig.2. Since the objective of [15] is only to balance, its objective function is $\boldsymbol{J}_{\mathbf{1}} 、 \boldsymbol{J}_{\mathbf{2}}$. Therefore, the scheduling scheme that minimizes $\boldsymbol{J}_{3}$ on the basis of its balance is shown in Tab.2.

Tab. 1 Working time for each task

\begin{tabular}{|c|c|c|c|c|c|c|c|c|c|c|c|c|c|c|c|}
\hline \multirow{2}{*}{$\begin{array}{c}\text { task } \\
\boldsymbol{i}\end{array}$} & \multicolumn{3}{|c|}{ working time/s } & \multirow{2}{*}{$\begin{array}{c}\text { task } \\
\boldsymbol{i}\end{array}$} & \multicolumn{3}{|c|}{ working time/s } & \multirow{2}{*}{$\begin{array}{c}\text { task } \\
\boldsymbol{i}\end{array}$} & \multicolumn{3}{|c|}{ working time/s } & \multirow{2}{*}{$\begin{array}{c}\text { task } \\
\boldsymbol{i}\end{array}$} & \multicolumn{3}{|c|}{ working time/s } \\
\hline & $t_{i A}$ & $t_{i B}$ & $t_{i C}$ & & $t_{i A}$ & $t_{i B}$ & $t_{i C}$ & & $t_{i A}$ & $t_{i B}$ & $t_{i C}$ & & $t_{i A}$ & $t_{i B}$ & $t_{i c}$ \\
\hline 1 & 2.5 & 2.5 & 2.5 & 11 & 3 & 0 & 0 & 21 & 17 & 19 & 18 & 31 & 3 & 3 & 3 \\
\hline
\end{tabular}

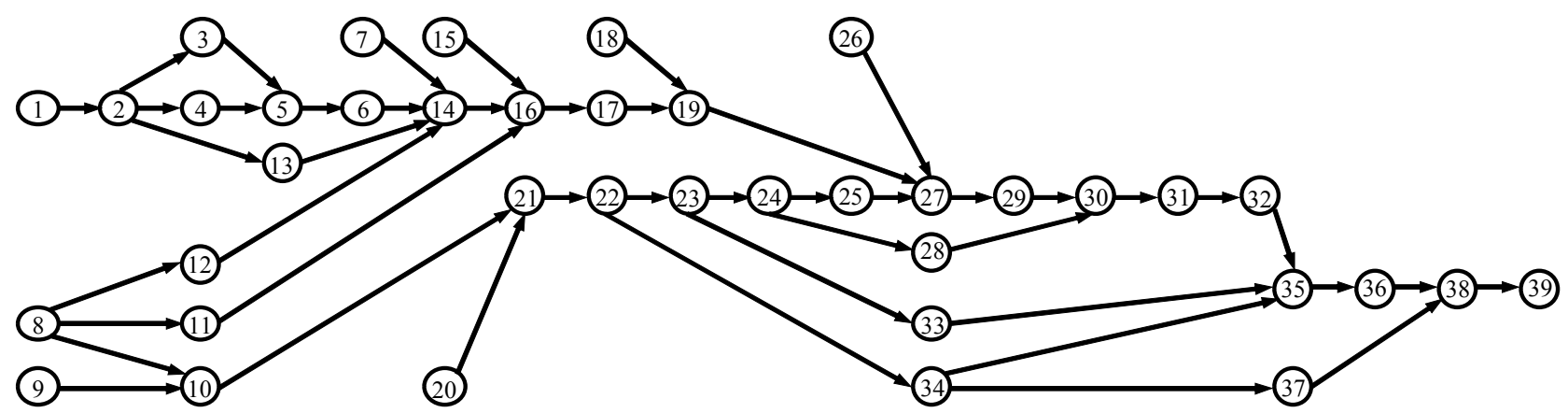

Fig. 2 Comprehensive job priority graph 
The proposed method is compared with the method in Ref. [15], PSO [27] and the Linear decreasing of inertia weight PSO (LDWPSO) [28]. The sequencing scheme from Ref. [15] was based on the optimized balancing results, and an exhaustive approach is used to find the optimization results. Due to the large feasible solution space, let the population size be 500 , number of iterations 200 , inertia weight $\omega=0.8, \omega_{\text {start }}=0.9, \omega_{\text {end }}=0.4$, $\boldsymbol{T}_{\mathbf{0}}=\mathbf{2 0 0}, \boldsymbol{T}_{\text {end }}=\mathbf{0 . 0 1}, \boldsymbol{\rho}=\mathbf{0 . 8}, \boldsymbol{c}=\mathbf{1}$. The optimization results of each algorithm are shown in the tab.23, fig.4-5.

Tab. 2 Workstation task allocation scheme and sequencing schemes of algorithms

\begin{tabular}{ccccc}
\hline & \multicolumn{4}{c}{ Workstation task allocation scheme corresponding to each algorithm } \\
& Ref.[15] & LDWPSO & PSO & proposed method \\
\hline Station1 & $(1,2,3,4,15,18,20,26)$ & $(1,2,3,4,8,9,10)$ & $(1,2,3,4,8,9,10)$ & $(1,2,3,4,8,9,10)$ \\
Station2 & $(5,9,13)$ & $(5,6)$ & $(5,6)$ & $(5,7,13)$ \\
Station3 & $(6,8,10,11,12)$ & $(12,20,21)$ & $(13,20,21)$ & $(12,20,21)$ \\
Station4 & $(21,22)$ & $(7,11,13,14,15)$ & $(7,12,14,22)$ & $(6,14,15)$ \\
Station5 & $(7,14,16,34,37)$ & $(16,18,22,23)$ & $(11,15,16,17,18,23)$ & $(11,16,18,22,23)$ \\
Station6 & $(17,23,24,25,28)$ & $(17,19,24,25,26,28)$ & $(19,24,25,26,27,28)$ & $(17,19,24,25,26,28)$ \\
& $(19,27,29,30,31$, & $(27,29,30,31,32,33$, & $(29,30,31,32,33$, & $(27,29,30,31,32,33$, \\
Station7 & $32,33,35,36,38,39)$ & $34,35,36,37,38,39)$ & $34,35,36,37,38,39)$ & $34,35,36,37,38,39)$ \\
Sequencing Schemes & ACABBACAC & ACACABABC & BACACACBA & BCAAAACBC \\
\hline
\end{tabular}

Tab. 3 Comparison of target values of each algorithm

\begin{tabular}{ccccccccc}
\hline $\begin{array}{c}\text { Objective } \\
\text { function }\end{array}$ & \multicolumn{3}{c}{ The target value of each algorithm } & \multicolumn{4}{c}{ Target ranking of each algorithm } \\
& Ref.[15] & LDWPSO & PSO & proposed met- & Ref.[15] & LDWPSO PSO & proposed method \\
\hline J1 & 0.45 & 0.79 & 2.08 & 0.62 & 1 & 3 & 4 & 2 \\
J2 & 7.71 & 7.47 & 7.52 & 7.06 & 4 & 2 & 3 & 1 \\
J3 & 4.89 & 3.90 & 5.62 & 3.74 & 3 & 2 & 4 & 1 \\
J & 4.38 & 3.99 & 5.29 & 3.78 & 3 & 2 & 4 & 1 \\
\hline
\end{tabular}
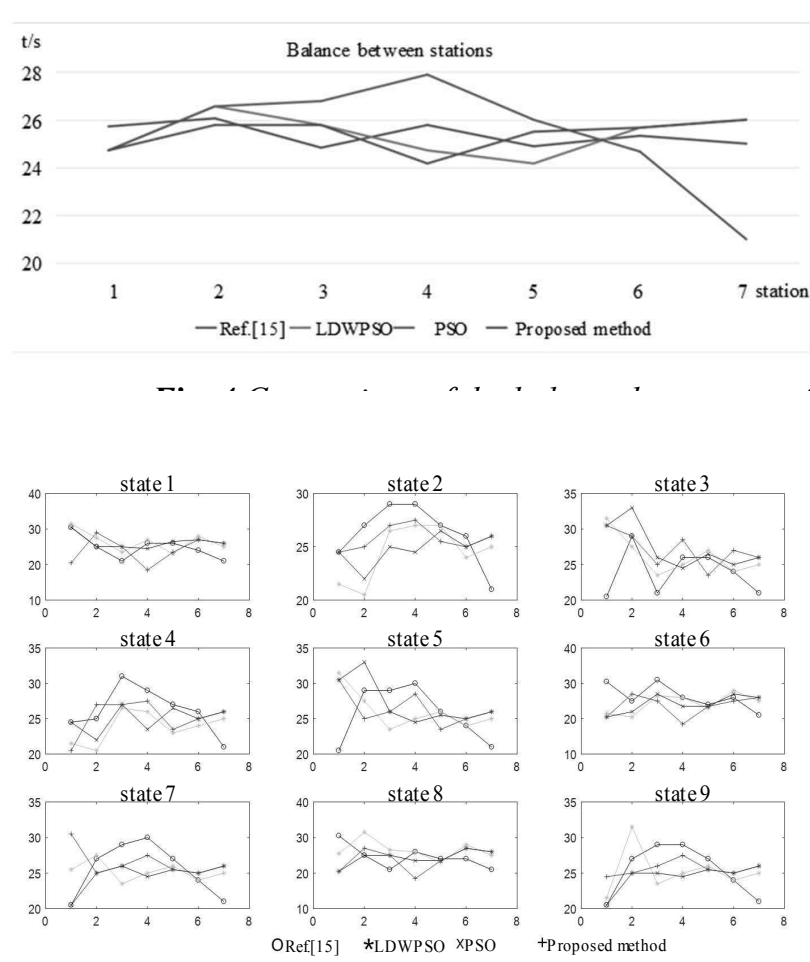

Fig. 5 Comparison of each state's dynamic balance of each algorithm

Tab.2-3 and Fig.4-5 indicate that the proposed method is better than Ref.[15], LDWPSO, PSO except objective function 1. Although the results from Ref.[15] are optimal for balancing among stations, but it can't be optimal on other optimization goals. This verifies the corollary of

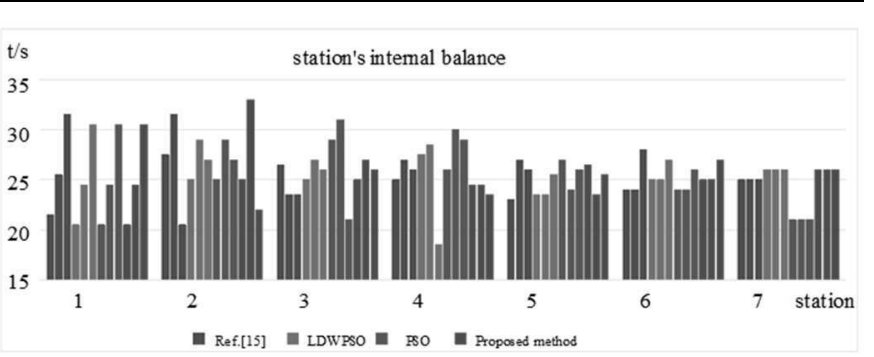

and station's internal balance of each algorithm

this paper, if a serial optimization method is used, the feasible region for optimal solutions is inevitably reduced during the balancing and sequencing optimization processes.

The relationship between the target value of each algorithm and the number of iterartions

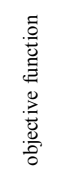

LDWPSO

Proposed method

evolution iterations

Fig. 6 Three algorithms iterative process and optimization results

This may lead to ignore the global optimal solutions. Fig.4-5 indicate that LDWPSO and the proposed method 
have better results in balancing among stations and dynamic balancing of stations than PSO and Ref.[15]. In addition, the iterative process and the final optimization target value in Fig. 6 indicate that the PSO algorithm converges prematurely and only local optimal solution is obtained. Thus, the proposed method can achieve better results than the other three methods in the overall optimization results.

In order to further verify the rationality of the proposed method, we used a case [29] of 19 tasks for analysis. The case has three different number of workstations and the different proportion of production, which has three different scenarios. Thom1 has a ratio of 5:2:9 for three products and five workstations. Thom 2 has a ratio of 2:3:4 for three products and four workstations. Thom3 has a ratio of $1: 2: 5$ for three products and three workstations. The resulting workstation task allocation and sequencing schemes are shown in Tab.4. The objective function values obtained are shown in Tab.5. The case analysis results show that the proposed method has more potential in searching comprehensive solutions.

Tab. 4 Workstation task allocation and sequencing schemes of algorithms

\begin{tabular}{|c|c|c|c|c|c|c|c|}
\hline $\begin{array}{c}\text { Prob- } \\
\text { lem }\end{array}$ & Method & Sequence & Station 1 & Station2 & Station3 & Station4 & Station5 \\
\hline \multirow{3}{*}{$\begin{array}{c}\text { Thom } \\
1\end{array}$} & Ref.[15] & $\begin{array}{c}\text { ACCCBACCCBACA } \\
\text { ACC }\end{array}$ & $(2,5,4,11)$ & $(13,17,1,7)$ & $(6,8,12,14)$ & $\begin{array}{c}(18,19,3,10,16 \\
, 9)\end{array}$ & (15) \\
\hline & $\begin{array}{c}\text { LDWPS } \\
\mathrm{O}\end{array}$ & $\begin{array}{c}\text { ACCCACABCACCC } \\
\text { ABC }\end{array}$ & $(2,5,4,11)$ & $(13,17,14,1)$ & $(7,8,12)$ & $(19,18,6,3,9)$ & $\begin{array}{c}(15,10,1 \\
6)\end{array}$ \\
\hline & $\begin{array}{c}\text { Pro- } \\
\text { posed } \\
\text { Method }\end{array}$ & $\begin{array}{c}\text { CBCCCAABCACCC } \\
\text { AAC }\end{array}$ & $(5,2,4,11)$ & $(14,13,17,1)$ & $(7,6,19,8)$ & $\begin{array}{c}(12,18,3,16,10 \\
)\end{array}$ & $(9,15)$ \\
\hline \multirow{3}{*}{$\begin{array}{l}\text { Thom } \\
2\end{array}$} & Ref.[15] & CCBCCACB & $(2,4,3,10,9)$ & $(8,5,11,13,14,18)$ & $(1,7,6,12,16,17)$ & $(19,15)$ & \\
\hline & $\begin{array}{l}\text { LDWPS } \\
\mathrm{O}\end{array}$ & CССВBCAC & $(4,2,5,11)$ & $(13,3,10,9,8,14,18)$ & $\begin{array}{c}(1,6,17,19,16,7 \\
12)\end{array}$ & (15) & \\
\hline & $\begin{array}{c}\text { Pro- } \\
\text { posed } \\
\text { Method }\end{array}$ & $\mathrm{BBCCCCCA}$ & $(4,2,5,11,3)$ & $(10,9,13,14,18,1)$ & $(6,8,17,19,7,12)$ & $(16,15)$ & \\
\hline \multirow{3}{*}{$\begin{array}{c}\text { Thom } \\
3\end{array}$} & Ref.[15] & CCABCBBAC & $(2,4,8,5,11,13,17)$ & $\begin{array}{c}(14,19,18,3,10,9,1 \\
6,1)\end{array}$ & $(7,12,6,15)$ & & \\
\hline & $\begin{array}{c}\text { LDWPS } \\
\mathrm{O}\end{array}$ & CCBABBACC & $\begin{array}{c}(3,5,4,10,11,13,17, \\
2,8)\end{array}$ & $\begin{array}{c}(1,6,7,14,18,19,12, \\
16)\end{array}$ & $(9,15)$ & & \\
\hline & $\begin{array}{c}\text { Pro- } \\
\text { posed } \\
\text { Method }\end{array}$ & CACCBABBC & $\begin{array}{c}(2,8,4,5,11,13,17,1 \\
4)\end{array}$ & $(18,19,1,7,12)$ & $(6,3,10,9,16,15)$ & & \\
\hline
\end{tabular}

Tab. 5 Comparison of target values of algorithms

\begin{tabular}{cccccc}
\hline Problem & Method & $\mathrm{J} 1$ & $\mathrm{~J} 2$ & $\mathrm{J3}$ & $\mathrm{J}$ \\
\hline \multirow{3}{*}{ Thom1 } & Ref.[15] & 0.57 & 0.26 & 21.01 & 12.772 \\
& LDWPSO & 0.62 & 0.34 & 20.75 & 12.642 \\
& Proposed Method & 0.59 & 0.27 & 14.99 & 9.166 \\
\hline \multirow{3}{*}{ Thom2 } & Ref.[15] & 0.6 & 0.26 & 9.64 & 5.956 \\
& LDWPSO & 0.78 & 0.25 & 11.28 & 6.974 \\
& Proposed Method & 0.76 & 0.36 & 9.12 & 5.696 \\
\hline \multirow{2}{*}{ Thom3 } & Ref.[15] & 0.66 & 0.35 & 8.17 & 5.104 \\
& LDWPSO & 0.98 & 0.32 & 14.78 & 9.128 \\
& Proposed Method & 0.76 & 0.34 & 7.93 & 4.978 \\
\hline
\end{tabular}

\section{Conclusions}

There are two problems in MMAL, i. e. sequencing and balancing, which need to be solved simultaneously. This paper develops a parallel model to optimize balancing and sequencing problems of the MMAL based on multiple objectives of load balance between stations, station's internal balance and dynamic balance in different working states. The proposed dynamic balance has more practical significance. An improved PSO algorithm combined with SA was proposed to solve the parallel optimization model, the length of the particle string includes both the amount of mixed line tasks and the minimum proportion of mixed products. This paper adopts a new mechanism of joint selection, the evaluation of the average change of the overall fitness is used as a basis for judging whether to enter the convergence, so as to make a decision whether to jump into the SA algorithm.

Comparing with traditional PSO and LDWPSO, the results show that the proposed algorithm can avoid premature entry into local convergence and obtain better optimization results. In addition, the results indicate that the serial optimization method cannot achieve the optimal results in the station' $\mathrm{s}$ internal balance and dynamic balance when the optimal load balance between stations is obtained. This also demonstrates the idea of this paper, 
serial optimization has the problem of lost domain, which makes it difficult to get the optimal solution in the process of comprehensive optimization.

\section{Acknowledgement}

The authors gratefully acknowledge the financial support provided by Fujian science and technology planning project(2017H6020).

\section{References}

[1] ZHANG, Z., \& SHARIFI, H. (2007). Towards theory building in agile manufacturing strategya taxonomical approach. IEEE Transactions on Engineering Management, Vol.54, no.2, pp.351370.IEEE, USA.

[2] UDDIN, M. K., SOTO, M. C., \& LASTRA, J. L. M. (2010). An integrated approach to mixed model assembly line balancing and sequencing. Assembly Automation, Vol.30, no.2, pp.164-172. Emerald group publishing Ltd, England.

[3] ÖZTÜRK, C., TUNALI, S., HNICH, B., \& ÖRNEK, A. (2013). Balancing and scheduling of flexible mixed model assembly lines with parallel stations. Constraints, Vol.67, no.9-12, pp.25772591. Springer, Netherlands.

[4] BAUTISTA, J. (2011). Procedures for the time and space constrained assembly line balancing problem. European Journal of Operational Research, Vol.212, no.3, pp.473-481. Elsevier B.V., Netherlands.

[5] BAUTISTA, J. (2011). Solving mixed model sequencing problem in assembly lines with serial workstations with work overload minimisation and interruption rules. European Journal of Operational Research, Vol.210, no.3, pp.495-513. Elsevier B.V., Netherlands.

[6] BAUTiSTA, J., ALFARO, R., \& BATALlA, C. (2015). Modeling and solving the mixed-model sequencing problem to improve productivity. International Journal of Production Economics, Vol.161, pp.83-95. Elsevier B.V., Netherlands.

[7] SALVESON, M. E. (1955). The assembly line balancing problem. Journal of Industrial Engineering, Vol.29, no.10, pp.55-101. National Bureau of Standards, USA.

[8] JACKSON, J. R. (1956). A computing procedure for a line balancing problem. Management Science, Vol.2, no. 3, pp.261-271. Informs.Germany.

[9] ALI, Z., WOO, M., \& GHAFOOR, A. (2014). Simultaneous balancing and sequencing of mixedmodel parallel two-sided assembly lines. International Journal of Production Economics, Vol.158, no.12, pp.314-333. Taylor \& Francis Ltd, England.
[10] GAGNON, R. J., \& GHOSH, S. (1991). Assembly line research: historical roots, research life cycles and future directions. Omega, Vol.19, no.5, pp.381-399. Elsevier Ltd, United Kingdom.

[11] NILAKANTAN, J. M., LI, Z., TANG, Q., \& NIELSEN, P. (2017). Milp models and metaheuristic for balancing and sequencing of mixed-model two-sided assembly lines. European Journal of Industrial Engineering, Vol.11, no.3, pp.353379. Inderscience enterprises Ltd, Switzerland.

[12] FACCIO, M., GAMBERI, M., \& BORTOLINI, M. (2016). Hierarchical approach for paced mixed-model assembly line balancing and sequencing with jolly operators. International Journal of Production Research, Vol.54, no.3, pp.761-777. Taylor \& Francis Ltd, England.

[13] BUKCHIN, Y. (2006). A branch-and-bound based solution approach for the mixed-model assembly line-balancing problem for minimizing stations and task duplication costs. European Journal of Operational Research, Vol.174, no.1, pp.492-508. Elsevier B.V., Netherlands.

[14] ZHANG YAHUI, HU XIAOFENG, \& WU CHUANXUN. (2016). Multi-objective two-sided assembly line rebalancing problem based oneconstraint method. Computer Integrated Manufacturing Systems. Vol.22, no.11, pp.2551-2562. Elsevier Ltd, United Kingdom.

[15] YU ZHAOQIN, SU PING (2008). Combining genetic algorithm and simulation analysis for mixed-model assembly line balancing problem. Computer Integrated Manufacturing Systems. Vol.14, no.6, pp.1120-1129. Elsevier Ltd, United Kingdom.

[16] YANG, C., GAO, J., \& SUN, L. (2013). A multiobjective genetic algorithm for mixed-model assembly line rebalancing. Computers \& Industrial Engineering, Vol.65, no.1, pp.109-116. Elsevier Ltd, United Kingdom.

[17] R. GAMBERINI, E. GEBENNINI, A. GRASSI, \& A. REGATTIERI. (2009). A multiple singlepass heuristic algorithm solving the stochastic assembly line rebalancing problem. International Journal of Production Research, Vol.47, no.8, pp.2141-2164. Taylor \& Francis Ltd, England.

[18] YANG, C.J.,GAO, J., SUN, L.Y.(2013).Multiobjective assembly line rebalancing: Model and algorithm.Systems Engineering-Theory \& Practice, Vol.33, no.08, pp.1956-1964. Elsevier Ltd, United Kingdom.

[19] ONUR SERKAN AKGÜNDÜZ, \& SEMRA TUNALI. (2010). An adaptive genetic algorithm approach for the mixed-model assembly line sequencing problem. International Journal of Production Research, Vol.48, no.17, pp.51575179. Taylor \& Francis Ltd, England. 
[20] PONNAMBALAM S.G., ARAVINDAN P., RAO M.S. (2003). Genetic algorithms for sequencing problems in mixed model assembly lines. Computer \& industrial engineering. Vol.45, no.4, pp.669-690. Elsevier Ltd, United Kingdom.

[21] BAUTISTA, J. (2011). Solving mixed model sequencing problem in assembly lines with serial workstations with work overload minimisation and interruption rules. European Journal of Operational Research, Vol.210, no.3, pp.495-513. Elsevier B.V., Netherlands.

[22] QIONG ZHU, \& JIE ZHANG. (2011). Ant colony optimisation with elitist ant for sequencing problem in a mixed model assembly line. International Journal of Production Research, Vol.49, no.15, pp.4605-4626. Taylor \& Francis Ltd, England.

[23] LU, J. S., WENG, Y. W., LI, X. L., TANG, H. T., \& DONG, Q. Y. (2014). Application of hybrid artificial bee colony algorithm in mixed assembly lines sequencing. Computer Integrated Manufacturing Systems, Vol.20, no. 1, pp.121127. Elsevier Ltd, United Kingdom.

[24] LU, J. S., WENG, Y. W., LI, X. L., TANG, H. T., \& DONG, Q. Y. (2014). Application of hybrid artificial bee colony algorithm in mixed assembly lines sequencing. Computer Integrated
Manufacturing Systems, Vol.20, no. 1, pp.121127. Elsevier Ltd, United Kingdom.

[25] MERENGO, C., NAVA, F., \& POZZETTI, A. (1999). Balancing and sequencing manual mixedmodel assembly lines. International Journal of Production Research, Vol.37, no. 12, pp.28352860. Taylor \& Francis Ltd, England.

[26] FACCIO, M., GAMBERI, M., \& BORTOLINI, M. (2016). Hierarchical approach for paced mixed-model assembly line balancing and sequencing with jolly operators. International Journal of Production Research, Vol.54, no.3, pp.1-17. Taylor \& Francis Ltd, England.

[27] EBERHART, R., \& KENNEDY, J. (2002). A new optimizer using particle swarm theory. International Symposium on MICRO Machine and Human Science (pp.39-43). IEEE. USA.

[28] SHI Y H , EBERHART R C(1998). A modified particle swarm optimizer.Proceedings of the IEEE Congresson Evolutionary Computation, (pp.69-73).IEEE, USA.

[29] KIM, Y. K., KIM, J. Y., \& KIM, Y. (2000a). A co-evolutionary algorithm for balancing and sequencing in mixed model assembly lines. Applied Intelligence, 13(3), 247-258. 